\title{
Is The Bloomberg System a Bastion of Privilege or an Education Essential?
}

\author{
Ray Pullaro \\ Long Island University \\ Brookville, NY, USA \\ David S. Jalajas \\ Long Island University \\ Brookville, NY, USA
}

\begin{abstract}
This paper set out to determine whether there is a relationship between the ranking of business programs and access to Bloomberg Professional Service, a proprietary data, analytics and information-delivery service. A set of top-ranked institutions was identified using two well-known survey rankings and selecting the top twenty schools from each. A random selection from the "unranked" schools listed in one survey was used to determine those schools to be compared to the top-ranked set. A combination of search and content analysis were utilized for data collection by examining institutions' websites, course catalogs and in some cases, by calling directly to inquire about Bloomberg access. The data were analyzed in bivariate tables to determine the existence of a relationship. The results found support for the research questions suggesting that higher-ranked institutions had access to the Bloomberg system in greater proportion than lower-ranked institutions.
\end{abstract}

Keywords: Is the Bloomberg System a Bastion of Privilege or Education Essential? Business education, engaged learning, Bloomberg, college ranking, technology, information studies

\section{Introduction}

To survive in the business of financial information, companies had to broaden focus beyond a single capital market sector like equities. A firm possessing the combination of real-time, proprietary news along with real-time market data created a strategic advantage. Going beyond just news, a firm that also provided a communication link among users was increasingly desirable. By 1981, Michael Bloomberg, along with several partners, realized this and launched Bloomberg, L.P. The firm created a platform that would provide access to data and analytics across the entire capital market spectrum. Bloomberg News, today with 150 bureaus in 73 countries publishes over 5,000 stories each day and is integrated into that service. ${ }^{1}$ Users can communicate with Bloomberg Messaging Service (also integrated into the Bloomberg system) and execute bilateral trades securely. With this suite of offerings, Bloomberg has become a market standard, albeit one that is difficult to learn and even harder to master. Our contention is that college graduates with training in the use of the Bloomberg system will be better prepared for employment in the financial services industry than those without such training. In this paper, we consider whether such training is more prevalent in the top-ranked universities than in the lower-ranked schools. Furthermore, we explore the extent to which schools that employ the Bloomberg system promote its use in their websites.

\subsection{Background}

How does one individual accumulate more wealth than all but seven people on the planet Earth? In the case of 74-year-old Michael Bloomberg, ranked number eight on Forbes 2016 list of "The World's Billionaires," he utilized data collection, knowledge organization and information retrieval. His eponymous, "Bloomberg Terminals," have become an essential tool for anyone working in the financial markets industry. Typically leased in pairs and ubiquitous on Wall Street despite a punitive cost structure, the demand for this self-contained, proprietary information system has been a source of steady profits for the former mayor of New York City. Although a financial institution would have the resources to afford Bloomberg terminals, their high cost might discourage a university from purchasing the terminals for use in training students. There are virtually no discounts for leasing Bloomberg terminals. The fee for a single terminal is 2,090 USD per month. If a customer leases three or more terminals, the fee is reduced to 1,830 USD per month per terminal. There is, however, a substantial discount for non-profit, accredited, institutions of higher learning. 
For every three terminals leased by such an institution, they receive nine "free" leases. ${ }^{3}$ Nonetheless, for a college to offer, say, 12 terminals to its students and faculty, the annual lease amounts to $65,880 \mathrm{USD}$, a substantial expense for all but the best-endowed institutions.

\subsection{History}

The technology used for transmitting and analyzing financial data began with ticker tape. Ticker tape first appeared in 1863 and held sway over the transmission of "real-time" stock market data for nearly a century. Prices were printed with ink on paper rolls (tape) in real-time, as long as the number of transactions did not exceed the speed at which they could be printed. This was the case on October 29, 1929. Known today as "Black Tuesday," the historic stock market crash actually began on the previous Thursday when the market lost more than 10 percent as the market opened on heavy training. The conventional means of transmitting price changes using ticker tape proved severely inadequate in handling such high volume. This resulted in long delays in reported prices, which exacerbated the market disruption.

Modern computers and electronic displays eventually replaced the mechanical ticker. The New York Quotation Company built their last ticker in 1960. The combination of the new computer technology along with ticker tape's limitations in terms of print speed, and the inconvenience of replacing tape and ink, led to the demise of this longstanding stock market information system.

In 1960, Quotron Systems developed a digital heir apparent to the mechanical ticker. This new system allowed brokers to receive stock market prices on their desktop computers. Not long after, other competitors looked to different areas of the capital markets, in addition to the stock market, to generate revenue and to compete with Quotron. Prior to 1969, obtaining the prices of other financial instruments involved calling various firms that dealt in those instruments. In 1969, Neil Hirsch founded Telerate Systems to computerize the communication of financial information in these other areas. In 1992, Dow Jones, the news service organization, acquired Telerate and restructured the combined entity as Dow Jones Telerate, Inc. Also in the mid-1960s, long-established United Kingdom news company, Reuters Ltd., helped pioneer the transmission of stock market quotes by computer, mostly from across the Atlantic. Following the approach taken by Telerate to focus outside the equity markets, by 1973 the company launched Reuters Monitor Rates Service. This service provided a new an electronic marketplace for foreign exchange. In 1981, Reuters Monitor Dealing Service "went live, allowing foreign currency dealers to conclude trades over video terminals...a world first" (Company history, n.d.). In 1996, this service was enhanced to give customers access to historical data and real-time news. With the appetite for news, not in any way a new development, "a furious itch for novelty" (Smith, 1934, p. 284) was identified as early as $18^{\text {th }}$ century England during the rule of Queen Anne. Similarly, the desire for current news drove reporting from ad hoc reading of formal charters next to "the monthly gazette [which] was succeeded by the weekly and finally by the daily newspaper" (Eisenstein, 1983, p. 105). Today, through services like Reuters, news is delivered up-tothe-minute; essentially in real-time. Building on this progress, in 2002, the company added a messaging service allowing "financial professionals to communicate instantly with their colleagues and customers" (Company history, n.d.). This broad channel of communication was prized from the days of the first written charters, "frequently addressed to the general public - to 'those whom the present writing shall reach' or 'to all who shall hear and see this charter" (Clanchy, 1993, p. 85). In the case of Reuters, rather than relying on a royal or church emissary to read such a message aloud, an entire network could be reached with a click. By empowering their market data provision and news reporting and transmission with this powerful communication tool, Reuters changed the value offering of this type of service and secured their share of the market for financial information. In 2008, Reuters merged with Thompson Corporation, the news organization. This history reveals several strategies for success in the business of financial information. To survive, companies had to broaden their focus beyond a single capital market sector like equities. The combination of real-time, proprietary news along with real-time market data also created a strategic advantage. Beyond the news, providing a communication link among users was becoming increasingly desirable. By 1981, Michael Bloomberg, along with several partners, realized this and launched Bloomberg, L.P. This platform would provide access to data and analytics across the entire capital market spectrum. Bloomberg News, today with 150 bureaus in 73 countries, publishes over 5,000 stories each day ${ }^{4}$ and is integrated into the broader Bloomberg system. Users can communicate with the Bloomberg Messaging Service (also integrated into the system) and execute bilateral trades securely. With this suite of offerings, Bloomberg has become a market standard, albeit one that is difficult to learn and even harder to master. 
Given the tension between the importance of this information tool in the finance industry and the high cost of leasing access, how are university or college budget officers to determine the wisdom of such an investment? Deans and faculty in business or finance programs may feel an obligation to prepare students for the inevitability of using Bloomberg as part of a well-rounded education. As Webster noted in 1995, students are working in an economy "where adaptability and ongoing retraining are the norm... are key players in the information society, so long as they have been blessed by a first-rate education that endows them with the informational abilities to survive in a new and globalized economy" $(1995$, p. 3). Schools feel an obligation to help graduates find work, and it seems clear that students qualified in the Bloomberg system should enhance their employment opportunities. Alshammari (2014) and Jabr (2011) have explored the notion that technology can improve learning. Jabr (2011) stated that "Educational technology is a systematic operation used to design the process of learning and education in order to raise the adequacy [of] students and teachers" (p. 70). Alshammari (2014) in a study of the social networking in academic learning, concluded that "Students...need the opportunity to be involved in instructional experiences that effortlessly work in both face-to-face and online environments" (p. 101). The training of college students in the Bloomberg system addresses this concern. Wajcman (1991) also addressed the importance need for training in new technology. She said, "The sociology of work has become increasingly concerned with the issue of flexible specialization and neo-Fordism. The focus here tends to be on the potential for job enhancement presented by new technology" (Wajcman, 1991, p. 28). Given the direct link between facility with a prevalent productivity tool and employability, colleges that are able to promote their ability to train students in the technology of the Bloomberg system are likely to increase placements and concomitantly, enrollments. One place to look to address the above issues is in the highest-ranked college business programs in the United States. Comparing their actions and approaches to access to Bloomberg systems may serve as a guide to others in considering this budgetary decision. An unranked program that aspires to a higher place in the rankings, may benefit from assuming the behaviors and trappings of higher-ranked institutions. Therefore, the first hypothesis considered will be whether higher-ranked college business programs lease Bloomberg Terminals in greater proportion than lower-ranked institutions. We then test whether higher-ranked business programs "advertise" Bloomberg access on their websites in greater proportion than lower-ranked institutions. Our last hypothesis concerns whether higher-ranked schools are more likely to offer courses that prepare students to use Bloomberg systems (or explicitly utilize Bloomberg systems) than lower-ranked institutions.

\section{Research Questions}

RQ1: Is there a relationship between the ranking of business programs and access to the Bloomberg Professional Service?

RQ2: Do universities that invest in Bloomberg Professional Service access advertise this on their websites?

RQ3: Are top ranked university business programs more likely to offer courses with content specifically related to the training on or use of Bloomberg terminals?

\section{Method}

Several methods had to be employed to determine which colleges use Bloomberg terminals or the Bloomberg software system, because Bloomberg, L.P. does not release client data of any kind. First, a content analysis was performed on the college websites, examining the language and images that might indicate that students or faculty have access to the Bloomberg system. Second, direct phone inquiries were made to the institution using a general information number or a line to the relevant business or finance department. These calls were made but the resulting data collected was deemed to be suspect, however, for a number of reasons. For example, the phone inquiry sought to determine not only whether there was access to the Bloomberg system, but also how many terminals were available. Given the pricing structure where Bloomberg offers nine free terminals for every three leased, it is extremely unlikely that responses from three to eleven are accurate. A number of calls returned such results. Ten of 22 top-ranked institutions returned phone responses of "three" to "eleven." Eight of 26 unranked institutions returned answers that were similarly questionable. In addition, there were instances when a different response (number of terminals) was given when a second call was made to an institution. Finally, there were four cases where a direct answer was not given during the phone conversation. Given these issues, it was necessary to support the phone inquiry with a content analysis. Two popular survey rankings were used to define whether a school was considered "top ranked" or "unranked." These surveys were: U.S. News \& World Report "Best Grad Schools, Business 2017" and Bloomberg Business Week, "Best Business Schools, 2015." The top-twenty ranked institutions were selected from each of these surveys. 
Table 1 Top Twenty Business Schools from U.S. News (2017) and Bloomberg Business Week (2015)

\begin{tabular}{|l|l|l|}
\hline Rank & U.S News Graduate Business School Ranking & Bloomberg Business Week Graduate Ranking \\
\hline 1 & Harvard University & Harvard University \\
\hline 2 & University of Chicago & University of Chicago \\
\hline 3 & Stanford University & Northwestern University \\
\hline 4 & University of Pennsylvania & Massachusetts Institute of Technology \\
\hline 5 & Northwestern University & University of Pennsylvania \\
\hline 6 & Massachusetts Institute of Technology & Columbia University \\
\hline 7 & University of California- Berkeley & Stanford University \\
\hline 8 & Yale University & Duke University \\
\hline 9 & Dartmouth College & University of California- Berkeley \\
\hline 10 & Columbia University & University of Michigan \\
\hline 11 & University of Virginia & Yale University \\
\hline 12 & Duke University & University of Virginia \\
\hline 13 & University of Michigan & University of California- Los Angeles \\
\hline 14 & Cornell University & Dartmouth College \\
\hline 15 & University of California- Los Angeles & Emory University \\
\hline 16 & University of North Carolina & Cornell University \\
\hline 17 & University of Texas & University of North Carolina \\
\hline 18 & Carnegie Mellon University & Carnegie Mellon University \\
\hline 19 & Emory University & Rice University \\
\hline 20 & New York University & Washington University \\
\hline
\end{tabular}

Overlap was significant, with 18 of the same institutions appearing on both lists, thus yielding a combined total of 22 unique institutions across the two surveys (see Table 1). Although survey skeptics may object to the use of any ranking, the agreement between the two surveys may provide additional comfort to some that the set of topranked institutions used in this study is reasonable. Note that University of Texas and New York University appeared among the U.S. News top twenty, but not the Business Week Survey, while Rice University and Washington University appeared among the top twenty on the Business Week survey but not on the U.S. News survey. All four were used in this study. The "unranked" institutions also had to be defined. The selection of this group involved a choice. First, Bloomberg Business Week rankings only include 74 ranked institutions. These might all be considered competitive or top-ranked by some and would have been included had more schools been selected as "top-ranked" for this analysis. Therefore, this survey was not used in our pool of unranked institutions. Instead, unranked institutions were defined as those schools on the U.S. News \& World Report "Best Grad Schools, Business 2017" ranking listed as "Unranked." This survey listed 94 ranked institutions, 35 ranked institutions with ranking not provided, and 325 unranked institutions. The unranked schools were listed on 13 web pages in the survey, each page containing 25 unranked names. A random number generator was utilized to select two names from each of the pages. With the sets of top-ranked and unranked institutions determined, content could then be collected.

\subsection{Content Analysis}

The content analysis utilized the methodology developed by Neuendorf (2002, p. 49) which involves: examining the content, identifying and defining variables, and developing coding schemes. The content to be examined in this study was the material in the college website for each top-ranked and unranked institution in the study. Websites were examined using embedded search functions. Basic terms, such as "Bloomberg," "Bloomberg terminals," "Bloomberg training" were queried. In those cases where the initial search of the college website returned no results, the academic departments related to business or finance were clicked through and a visual search was performed page by page. An alternative would be to use software such as ATLAS or a spider-like content analysis tool to fully cover the site maps. We chose to use a more rudimentary approach because we felt it better reflected the likelihood of the public finding whether that school used the Bloomberg system. Therefore, the unit of data collection was the college website (for the first two research questions). For the third question, the unit of data collection was the course catalog. 
Table 2. Selection of Unranked Institutions from U.S. News Survey Using Random Number Generation

\begin{tabular}{|l|} 
Claremont Graduate University \\
\hline Clarion University of Pennsylvania \\
\hline Delaware State University \\
\hline Florida State University \\
\hline Idaho State University \\
\hline John Carroll University \\
\hline Midwestern State University \\
\hline Miami University \\
\hline Minnesota State University \\
\hline New Jersey Institute of Technology \\
\hline Radford University \\
\hline Sacred Heart University \\
\hline San Francisco State University \\
\hline Stephen F. Austin State University \\
\hline St. Mary's College of California \\
\hline SUNY Old Westbury \\
\hline University of Central Florida \\
\hline University of Dallas \\
\hline University of Montana \\
\hline University of North Florida \\
\hline University of Texas- Rio Grande Valley \\
\hline University of Texas- the Permian Basin \\
\hline University of Wisconsin- Oshkosh \\
\hline Utah State University \\
\hline William Paterson University \\
\hline Worcester Polytechnic Institute \\
\hline
\end{tabular}

Table 3 Relative Ranking of School by Access to Bloomberg Systems Identified by All Sources

\begin{tabular}{|l|l|l|l|}
\hline \multirow{2}{*}{ Relative Ranking of Schools } & \multicolumn{2}{|l|}{ Bloomberg Access identified by Website, Catalog, or Call } & \multirow{2}{*}{ Total } \\
\cline { 2 - 4 } High & Yes & No & 22 \\
& 22 & $(0)$ & $(45.8)$ \\
\hline \multirow{2}{*}{ Unranked } & $(59.5)$ & 11 & 26 \\
& 15 & $(100)$ & $(54.2)$ \\
\hline \multirow{2}{*}{ Total } & $(40.5)$ & 11 & 48 \\
& 37 & $(100.0)$ & $(100)$ \\
\hline
\end{tabular}

Note. Column percentages indicated in parentheses.

Table 4 Relative Ranking of School by Advertisement of Access to Bloomberg System

\begin{tabular}{|l|l|l|l|}
\hline \multirow{2}{*}{ Relative Ranking of Schools } & \multicolumn{2}{|l|}{ Bloomberg Access Advertised on Website or Catalog } & \multirow{2}{*}{ Total } \\
\cline { 2 - 4 } & Yes & No & \\
\hline \multirow{2}{*}{ High } & 19 & 3 & 22 \\
& $(65.5)$ & $(15.8)$ & $(45.8)$ \\
\hline Unranked & 10 & 16 & 26 \\
& $(34.5)$ & $(84.2)$ & $(54.2)$ \\
\hline Total & 29 & 19 & 48 \\
& $(100.0)$ & $(100.0)$ & $(100.0)$ \\
\hline
\end{tabular}

Note. Column percentages indicated in parentheses. 
Table 5 Relative Ranking of School by Presence of Bloomberg Images or Pictures Website

\begin{tabular}{|l|l|l|l|}
\hline \multirow{2}{*}{ Relative Ranking of Schools } & \multicolumn{2}{|l|}{ Bloomberg Image on Website } & \multirow{2}{*}{ Total } \\
\cline { 2 - 4 } & Yes & No & \\
\hline High & 4 & 18 & 22 \\
& $(66.7)$ & $(42.9)$ & $(45.8)$ \\
\hline Unranked & 2 & 24 & 26 \\
& $(33.3)$ & $(57.1)$ & $(54.2)$ \\
\hline Total & 6 & 42 & 48 \\
& $(100.0)$ & $(100.0)$ & $(100.0)$ \\
\hline
\end{tabular}

Note. Column percentages indicated in parentheses.

Table 6 Relative Ranking by Presence of Course with Bloomberg Content or Utilization

\begin{tabular}{|l|l|l|l|}
\hline \multirow{2}{*}{ Relative Ranking of Schools } & \multicolumn{2}{|l|}{ Bloomberg Course Available } & \multirow{2}{*}{ Total } \\
\cline { 2 - 4 } & Yes & No & \\
\hline High & 7 & 14 & 21 \\
& $(66.7)$ & $(42.9)$ & $(45.8)$ \\
\hline Unranked & 3 & 23 & 26 \\
& $(33.3)$ & $(57.1)$ & $(54.2)$ \\
\hline Total & 10 & 27 & 47 \\
& $(100.0)$ & $(100.0)$ & $(100.0)$ \\
\hline
\end{tabular}

Note. Column percentages indicated in parentheses.

Twenty-six schools were selected for the unranked category. They were chosen from 316 unranked schools in the U.S. News \& World Report "Best Grad Schools, Business 2017" survey. A random sample of the institutions was selected using the following method. The U.S. News website presents 25 schools per page. For each of these pages, the schools were numbered from 1 to 25 and a random number generator was used to generate two numbers to select schools for the sample. Beginning with the first unranked school and proceeding to the end, there were 13 pages yielding 26 schools for this study (see Table 2). The coding schema for the analysis of the websites in this study was relatively simple with four categories representing mutually exclusive and exhaustive coverage of the content. The categories were: Bloomberg language, image of a Bloomberg terminal or keyboard, a Bloomberg course, and "not found." An analogous coding system was applied to course catalogues for all of the schools selected in the ranked and unranked groups. The categories were: Bloomberg explicitly mentioned in the course title, or evidence of training in or use of the Bloomberg system explicitly mentioned in the course catalogue. To establish the existence of a relationship between two nominal variables, bivariate contingency tables were used. Whether a school was ranked or unranked was treated as the dependent variable and whether a school indicated the use of the Bloomberg system was treated as the independent variable. Four analyses were conducted. In the first, we compared all indicators of access to Bloomberg systems (including websites, telephone calls, and course catalogues) between the ranked and unranked schools (see Table 3). In the second analysis we compared the number of schools with advertisements regarding Bloomberg systems on their web pages (see Table 4). In the third analysis we compared the number of images or pictures on their websites referring to Bloomberg systems (see Table 5). In the fourth we compared the number of schools with courses in Bloomberg systems (see Table 6).

\section{Results}

The first research question asked whether there was a relationship between the ranking of business programs and access to the Bloomberg Professional Service.

An analysis of the contingency table in Table 3 showed phi coefficient of .50, indicating a "substantial relationship" (Davis, 1971, p. 49) between the ranking of the business program and the overall indications of access to the Bloomberg systems. The top-ranked schools were more likely to indicate access to the systems.

The second research question asked whether universities that invest in Bloomberg Professional Service access advertise this on their websites. We found that there was a "moderate relationship" (Davis, 1971, p. 49) between the advertising of Bloomberg systems and the ranking of the school $(p h i=.49)$. Top-ranked schools are more likely to advertise their access to Bloomberg systems (see Table 4). 
In Table 5 we focused on whether the schools used images referring to the Bloomberg terminals in their websites. We found a "low relationship" (Davis, 1971, p. 49) between the use of Bloomberg images on a school's website and their ranking $(p h i=.16)$. In the third research question we asked whether top-ranked university business programs were more likely to offer courses with content specifically related to the training on or use of Bloomberg terminals (see Table 6). We found a "moderate relationship (Davis, 1971, p. 49) between the ranking of the programs and whether the program offered courses in the Bloomberg system $(p h i=.31)$. Top-ranked schools were more likely to offer courses in the Bloomberg systems.

\section{Discussion}

The use of Bloomberg systems in the classroom and the attendant study of learning outcomes, job preparedness, and epistemology in general, appears to be in need of further research. Baudrillard (1994) might lament that with tools like Bloomberg available but hard to use or understand, "there is more and more information, and less and less meaning" (p. 79). Searches for the use of Bloomberg terminals or systems in the academic literature using both Social Science and Business databases returned limited results. Even among those results that were returned, many were periodicals, or at best only tangentially related to the realm of higher education in general. The paucity of research on the subject within the academic literature opens the door for a needed study. The Bloomberg system is difficult to use, but the mastery of it is prized on Wall Street. Even those steeped in research techniques find the system difficult, or as one research librarian described it, "a complex system, not easily or intuitively navigated" (Holler, 2007, p.3). There is no instruction manual provided and there appears to be a random taxonomy where "the thoughts of [users] are guided by the way the contents... are arranged and presented. Basic changes in...format might well lead to changes in thought patterns" (Eisenstein, 1983, p.71). Against the backdrop of this knowledge organization, the best pathways to mastery are use, experience and collaboration with those more familiar with the tool. Wajcman (1991) emphasized the importance of experience by noting, "Technological 'things' are meaningless without the 'know-how' to use them, repair them, design them and make them. That know-how often cannot be captured in words. It is visual, even tactile, rather than simply verbal or mathematical" (p. 14). These attributes make Bloomberg an ideal candidate for classroom instruction. Kuhn (1970) supports the importance of training to enhance intuitions. He says, "Intuitions... are not individual, [r]ather they are the tested and shared possessions of the members of a successful group, and the novice acquires them through training" (Kuhn, 1970, p. 191). In the context of technological innovations, this is another testament to the merits of bringing Bloomberg systems to the classroom. Students who end up working in a firm that uses Bloomberg systems will have a head start when they are prepared with such knowledge. This is an example of the specialization of knowledge and the development of "knowledge people as specialists and what gives them power" (Drucker, 1993, p. 47) that Drucker described in the shift toward a post-industrial society. Toffler would argue in "Third Wave" (Toffler, 1980) parlance, that as the "economy unfolds, the proletariat becomes the cognitariat" (p. 75), and educational institutions should be mindful of this dynamic.

\subsection{Limitations}

Although it is justified to select all of the top institutions from each survey for this analysis, drawing the line at the top twenty is arbitrary, but at a level where the typical user of these surveys will accept the perceived quality of the institutions as high. Although it would be possible to select a random sample of say the top 100 ranked institutions, again that line will be arbitrarily drawn. For this study, the top twenty institutions (yielding a total of 22 unique names) was used and since the population is small enough, "census content analysis [was] possible" (Wildemuth, 2009, p. 300). The literature on Bloomberg as an educational tool is very limited in the domains of Information Studies, Education, and Social Science. Although this leaves a wide berth for new research, it does make for extensive groundwork. Making the problem more intractable, college clubs, rather than classes, are often the vehicles that utilize the Bloomberg system. Identifying the usage of the Bloomberg system in those groups would be difficult.

\section{Conclusion}

Data collection via content analysis proved a reasonable, albeit time-consuming, approach. Telephone conversations were disappointing in terms of both lack of information and misinformation. A future study where calls are made to budget officers would likely increase the accuracy of this collection method. On the other hand, budget officers are perennially hard to reach and universally reluctant to share this type of information. 
Even visiting a physical location won't necessarily yield better results since Bloomberg licenses can reside on a laptop or in the office of a faculty member and do not always reside in a visible, accessible public setting. In the end, content analysis may still be required. Although a relationship between Bloomberg access and school ranking was demonstrated in this study, causality could not be established. Our assumption was that access to the Bloomberg system will lead to higher rankings. Training with such an important technology in the financial arena should lead to greater success for the students. However, a number of variables would need to be controlled to establish a causal relationship. Frankfort-Nachmius, Nachmius, and DeWaard (2015) emphasize that "If the effects of all relevant variables are controlled for and the relation between the original two variables is maintained, the relation is not spurious" (p. 50). An obvious candidate for control would be the size of the endowment. Another would be the operating budget. We have assumed that the ranked and unranked schools are equally capable of purchasing the Bloomberg system. For wealthier institutions, however, the expense required to provide access to Bloomberg systems may represent a much smaller portion of available funds. The cost of the system may affect the likelihood of a financially-challenged institution even being able to afford the product. Another variable to control for is student population. Combining this data with an accurate number of terminals available could lend insight on a per capita access, possibly a better measure of analysis. Another variable to consider would be the portion of graduates pursuing finance careers.

Time order should also be assessed to determine if the rankings of a school changed when they obtained access to Bloomberg systems. To establish this, a time series would need to be examined against changes in rank. A backward-looking analysis could be employed utilizing the Internet archives, also known as the "way back machine." In addition, a forward-looking analysis could be examined over subsequent years. This analysis would involve regressing ranking against Bloomberg access from acquisition date and would require a new sample.

In this study, the consistently higher percentage of top-ranked institutions relative to unranked institutions that have access to Bloomberg, advertise this fact on websites, or offer courses pertaining to Bloomberg systems, speaks to one set of behaviors of these institutions. The significance established with respect to displaying information about Bloomberg on websites, speaks to the emphasis on communicating this offering to prospective (and current) students. For the aspirational business program, following the lead of these high-ranked institutions may translate to a higher ranking based on appearance alone. This is not clear. But what is clear, as Wajcman (1991) states, is that "human beings do change and the introduction of machines alters people's preferences and values" (p. 92). So, it is only natural that educators consider how to respond to new technologies. Schools need to proactively determine which (if any) of these technologies merits a place in the curriculum. The more important question, epistemic in nature, asks whether students with access to Bloomberg systems come away from the experience with more knowledge than those without. And while this question makes no value judgment on what Habermas considers "the sort of information that is necessary for a democratic society" (Webster, 1995, p. 163), it is nonetheless a question worth answering.

\section{References}

Alshammari, N. (2014). The use of technology in education to improve student's reading skills in elementary schools, Saudi Arabia. International Journal of Business and Social Science, 5 (6), 69-71.

Baudrillard, J. (1994). Simulacra and Simulation. Ann Arbor: University of Michigan Press.

Clanchy, M. T. (1993). From Memory to Written Record: England 1066.1397. Oxford: Blackwell.

Company history. (n.d.). Retrieved from http://thomsonreuters.com/en/about-us/company-history.html.

Davis, J. A. (1971). Elementary Survey Analysis. Englewood Cliffs, NJ: Prentice-Hall.

Drucker, P. F. (1993). Post-capitalist Society. New York: Harper Business.

Eisenstein, E. L. (1983). The Printing Revolution in Early Modern Europe. Cambridge: Cambridge University Press.

Frankfort-Nachmius, C., Nachmius, D., \& DeWaard, J.. (2015). Research Methods in the Social Sciences, 8th Ed. New York, Worth Publishers.

Jabr, N. H. (2011). Social networking as a tool for extending academic learning and communication. International Journal of Business and Social Science, 2 (12), 93-102.

Kuhn, T. S. (1970). The Structure of Scientific Revolutions. Chicago: University of Chicago Press.

Holler, C. M. (2007). "Bloomberg's Global Product Certification Program Online: An Academic Business Librarian's Experience." Journal of Business \& Finance Librarianship, 13(1), 3-17.

Neuendorf, K. A. (2002). The Content Analysis Guidebook. Thousand Oaks, CA: Sage Publications. 
Smith, P. (1934). A History of Modern Culture. New York.

Toffler, A. (1980). The Third Wave. New York: Morrow.

Wajcman, J. (1991). Feminism Confronts Technology. University Park, PA: Pennsylvania State University Press.

Webster, F. (1995). Theories of the Information Society. London and New York: Routledge.

Wildemuth, B. M. (2009). Applications of Social Research Methods to Questions in Information and Library Science. Westport, CT: Libraries Unlimited.

\section{Footnotes}

${ }^{1}$ http://www.bloomberg.com/company/bloomberg-facts/

${ }^{2}$ Ahead of Bloomberg on the list are: 1-Bill Gates, 2-Amancio Ortega (Spanish owner of Zara stores), 3-Warren Buffet, 4-Carlos Slim Helu (Mexican telecom mogul), 5-Jeff Bezos, 6-Mark Zuckerberg and 7-Larry Ellison. It could be argued that aside from Ortega and Buffet, every one of these "world's richest" derived their wealth from information related business. http://www.forbes.com/billionaires/list/

${ }^{3}$ Pricing information made available by Bloomberg, L.P. sales representative, Peter Orlando, during face-to-face discussion on April 7, 2016. Mr. Orlando's can be contacted at porlando2@ bloomberg.netor +1-212-617-1387.

${ }^{4} \mathrm{http}: / / \mathrm{www} \cdot$ bloomberg.com/company/bloomberg-facts/ 